https://www.journal-imab-bg.org

Case report

OPEN ACCESS

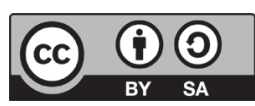

\title{
CASE REPORT ABOUT THE PROSTHETICS WITH INTRAOSSEOUS IMPLANTS OF THE MAXILLA
}

\author{
Desislava Konstantinova ${ }^{1}$, Anna Nenova-Nogalcheva ${ }^{2}$, \\ 1) Department Dental Material Science and Propedeutics of Prosthetic Dental \\ Medicine, Faculty of Dental Medicine, Medical University - Varna, Bulgaria \\ 2) Department Oral Surgery, Faculty of Dental Medicine, Medical University - \\ Varna, Bulgaria.
}

\begin{abstract}
:
During the rehabilitation of patients with the atrophic maxilla, the dental medicine doctor may faced before the challenge of achieving the exact placing of the intraosseous implants. We would like to present you the case of a 33year woman with a prosthetic of implants after a Rehermanns plastic. The clinical and radiographic examinations show an absorbed maxilla with the horizontal and vertical bone deficit. The patient used a placeholder till the complete bone restoration after the surgical intervention. She did not want a final rehabilitation of the defect using a bridge-like structure due to the necessary intervention of the teeth neigboring the defect. The decision about the placing of intraosseous implants was made after the CBCT examination. The control examinations made after 6 months, 1 year, 3 years, and 5 years show satisfying results in regard to the function and aesthetics, and also the lack of subjective sensation for the patient.
\end{abstract}

Keywords: intraosseous implants, bone absorption, bone deficit,

\section{INTRODUCTION}

The rehabilitation of the edentulous maxilla is a challenge due to the bone structure, the progressing heavy absorption after the edentulous jaw and the pneumatization of the maxillary sinus [1].

Recently the rehabilitation of partial or complete edentulousness with dental implants is widely used in dental practice $[2,3,4,5,6]$.

The quantity and quality of the available bone have their signature on achieving optimal therapeutic results with dental implants [7, 8].The adentia may cause serious absorption on the alveolar ridge and leave an inappropriate place for implants prosthesis. In these cases, for the proper fixing of the implant on the maxilla, it may be required to lift the maxillary sinus and ensure the place for the implant. The procedure reduces the need for surgical intervention related to autogenous grafts, as well as some of the limitations of the osteoconductive graft materials $[8,9]$.

\section{CASE REPORT PRESENTATION:}

The patient (33-year), without concomitant diseases visited our practice in regard to the appearance of a fistula in the area of tooth 25 and complaining of discomfort while eating and when both teeth row pressing, as well as pain at the back of the neck and the temporal area. Sometimes blockage of left nostril and secretion. Anamnestic report about dental manipulations in the past related to tooth devitalization due to complications after a serious carious defect. Objectively, during the intraoral examination, it was found out that tooth 24 and tooth 25 are covered with single cermet crowns for a long time. The exudating purulent fistula was established between the two teeth. The radiological examination was planned, and it showed that there is an inexactly completed endodontic treatment of teeth 24 and 25. There were radiological data for odontogenous cyst around the apex of 25th, changing into the maxillary sinus (Fig.1 and 2).

Fig. 1. Orthopantomography

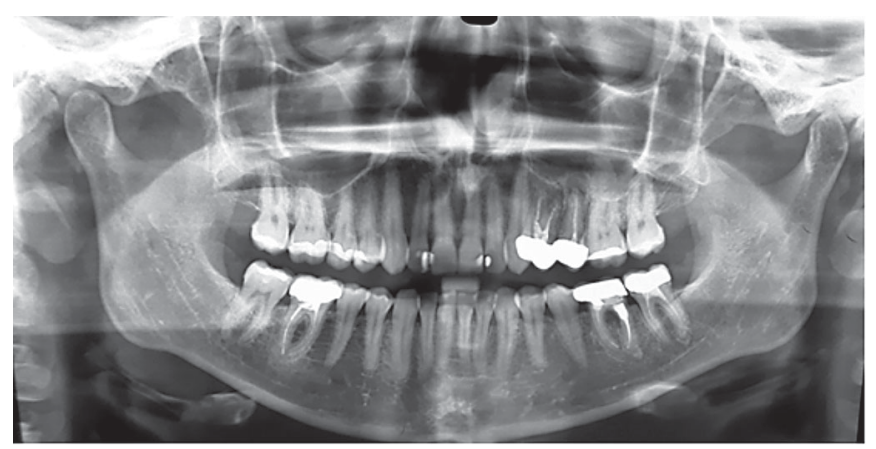

Fig. 2. Sectoral radiography, regio 24,25
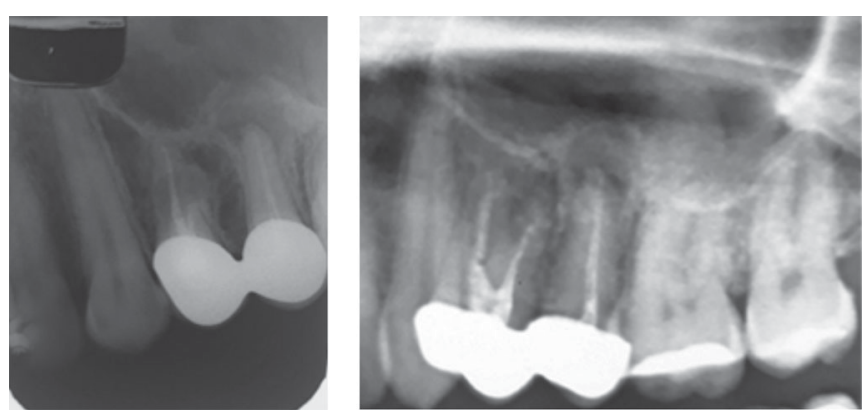
After consultation with an endodontist, due to the lytic changes in the bone, a decision was made to perform a surgical treatment. It was carried out under conducting local anaesthesia. After the dissection of the mucoperichondrial flap, using a bone cutter, vestibular access to the compact was made, the cyst formation was carefully dissected, as it was in contact with the sinus cavity, and teeth 24 and 25 were extracted. After flushing with antiseptic solutions, a Rehermann's plastic was made for the cavity. The histological result showed a chronically inflamed radicular cyst.

The post-surgical period was smooth, the wound was calm. The outcome of the disease was a partial defect of the upper jaw.

A month after the surgical treatment, the replaceable placeholder was fixed till the final restoration of the bone cut and the preparation of a plan for denture restoration.

A computerized tomographic examination was made in six months for following on the progress of the restoration process and subsequent implantological treatment of the patient. Examination technique: lentulo spiral, axial cuts in $1 \mathrm{~mm}$ with subsequent reconstructions in 3D under "Dental CT" protocol. The result showed that the maxillary sinus is lightening normally.

An incision in the area of teeth 24 and 25 was performed under local anaesthesia, located 2-3 $\mathrm{mm}$ along with the palatal and relieving cuts in the distal end of the adjacent teeth. TBR Periosave $\mathrm{M}$ implants of size $3,2 \mathrm{~mm} / 8 \mathrm{~mm}$ were fixed.

The post-surgical period was calm, without particularities and allowed re-treatment of teeth 36, 37, 46 and endodontic treatment of tooth 25, Fig 3.

Fig. 3. OPG 6 months after fixing of intraosseous implants

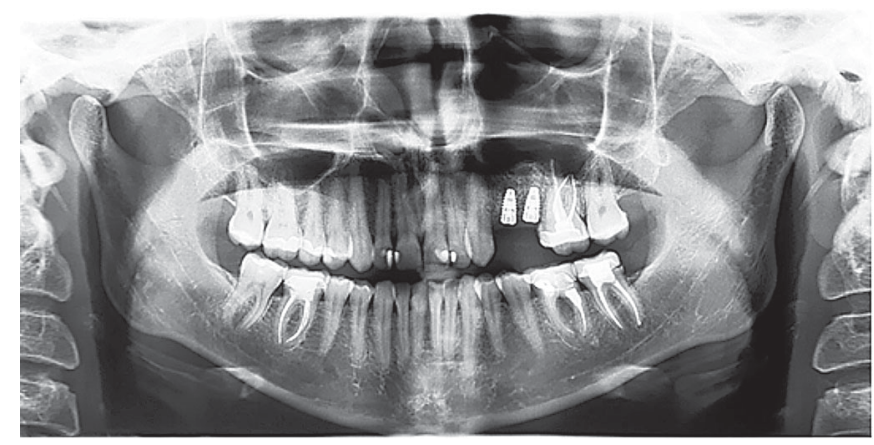

Disclosing of implants was done 6 months later, and gingiva formers were placed.

Prosthetics was carried out with standard abutments (tooth $24-0^{\circ}$, and for tooth $25-15^{\circ}$ inclination), Fig. 4.
Fig. 4. Intraoral view of maxilla after abutment placing

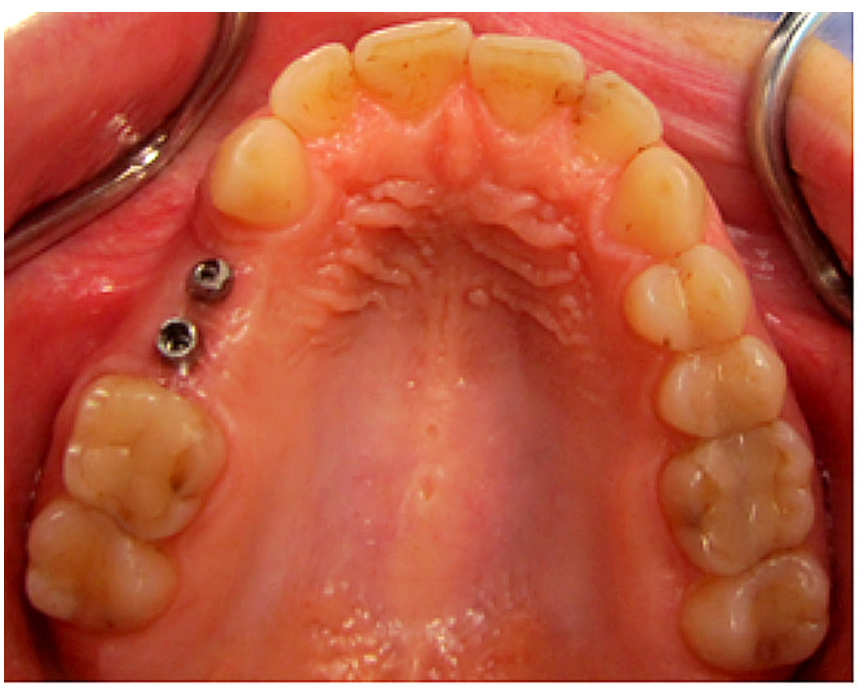

Prosthetics was made using single PFM crowns, Fig. 5

Fig. 5. Prosthetics with ceramic-metal crowns of tooth 24 and tooth 25
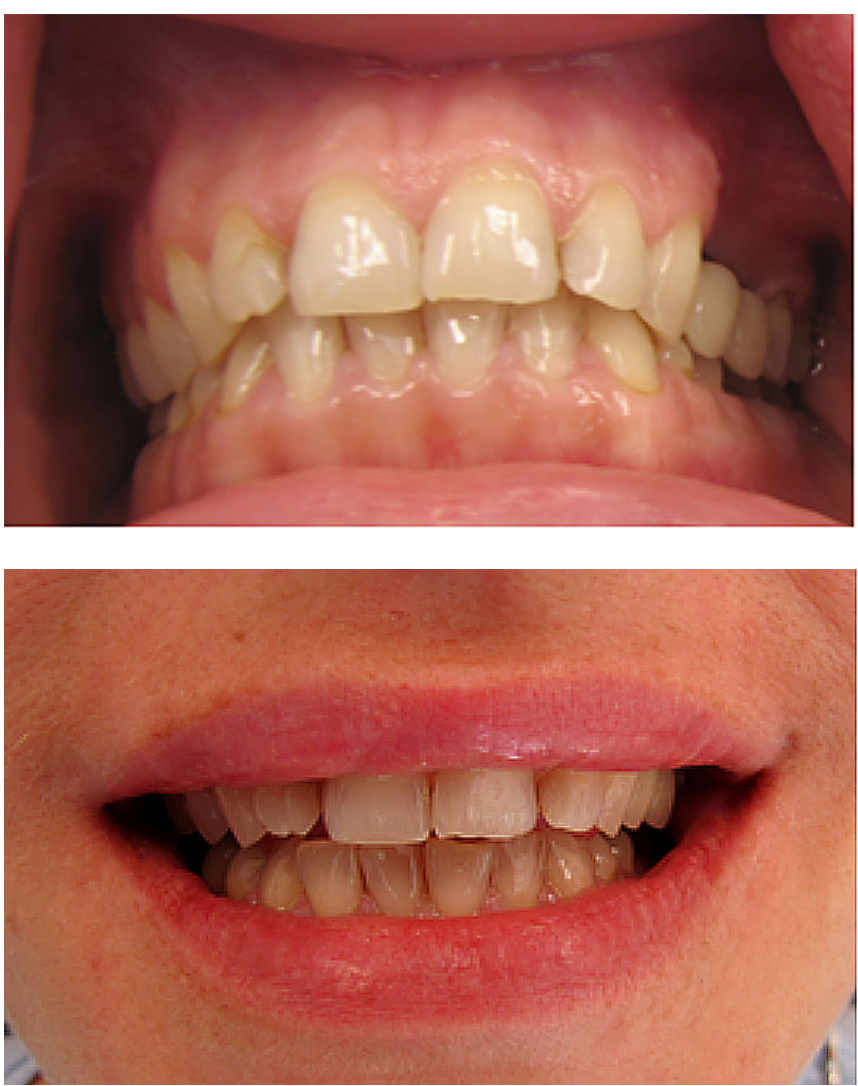

Follow-up was carried out in 6 months, 1 year, 3 years and 5 years. The result is satisfying in regard to the function and aesthetics and also lack of subjective sensation for patient, Fig. 6 . 
Fig. 6. Intraoral view of the maxilla 5 years after the intervention

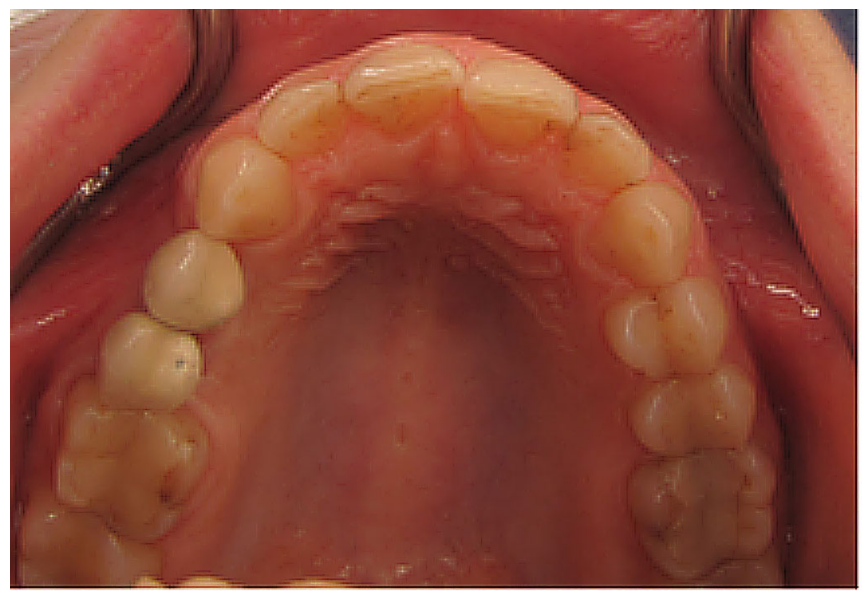

\section{DISCUSSION:}

Many studies prove that the minimum height of the bone that allows the use of an intraosseous implant is 10 $\mathrm{mm}$ and the width - minimum $5 \mathrm{~mm}[10,11,12,13,14]$. Ariji and others face this type in $56 \%$ of the cases of adentia dating up to five years [15]. It is accepted that the bone height of $5-10 \mathrm{~mm}$, if the bone width is sufficient (minimum $5 \mathrm{~mm}$ ), requires either lifting of the sinus bottom or bone augmentation if the bone width is $2,5-5 \mathrm{~mm}$, as this is done before implant installation. According to sci- entific studies, this type is faced in $32 \%$ of the cases of adentia occurring 5-10 years ago, without prosthesis treatment [15]. In case of bone height of 0-5 mm, lifting of the bottom of the maxillary sinus is necessary and delayed implant installation. This type shows in $12 \%$ of the cases, as the adentia is dated more than 10 years, and no prosthesis treatment is carried out [7].

Increasing the contact surface between the bone and the implants is important for successful and predictable osteointegration. It is proved that increasing the size (both length and width) of the implant from both dimensions reduces the stress passing on the adjoining bone [16, 17].

The resulting response of bones and soft tissues after the intraosseous fixing of dental implant is controlled by factors for healing wounds (cytokines, chemokines and growth factors); it is influenced by the biomechanics (gravitational, functional and therapeutic load); and the mineral metabolism (hormones, diet and excretion) $[1,17,18,19,20]$. The long-term support of the implant interface requires continuous bone remodeling.

\section{CONCLUSION:}

Due to the complexity of the tissue's response and the osteointegration, dental implants may be influenced by many factors, including age, diet, medicines, systematic illness and oral diseases. Nevertheless, this should be the first means when making a decision about the rehabilitation of teeth row.

\section{REFERENCES:}

1. Wallace SS. Lateral window sinus augmentation using bone replacement grafts: A biologically sound surgical technique. Alpha Omegan. 2005 Jul;98(2):36-46. [PubMed]

2. Chiapasco M, Zaniboni M. Clinical outcomes of GBR procedures to correct peri-implant dehiscences and fenestrations: a systematic review. Clin Oral Impl Res. 2009 Sep; 20(Suppl 4):113-23. [PubMed]

3. Patel J, Antov H, Nixon P. Implant-supported oral rehabilitation in oncology patients: a retrospective cohort study. Br J Oral Maxillofac Surg. 2020 Oct;58(8):1003-1007. [PubMed]

4. Huang MF, Alfi D, Alfi J, Huang AT et al. The Use of Patient-Specific Implants in Oral and Maxillofacial Surgery. Oral Maxillofac Surg Clin North Am. 2019 Nov;31(4):593-600. [PubMed]

5. - García-Minguillán G, Del Río J, Preciado A, Lynch CD, CastilloOyagüe R. Impact of the retention system of implant fixed dental restorations on the peri-implant health, state of the prosthesis, and patients' oral health-related quality of life. $J$ Dent. 2020 Mar;94:103298. [PubMed]

6. Albrektsson T, Branemark PI, Hansson HA, Lindstrom J. Osseointegrated titanium implants. Requirements for ensuring a long-lasting, direct bone-to-implant anchorage in man. Acta Orthop Scand. 1981; 52(2):15570. [PubMed]

7. Misch CE. Maxillary sinus augmentation for endosteal implants: Organized alternative treatment plans. Int J Oral Implantol. 1987; 4(2): 4958. [PubMed]

8. Eberhardt JA, Torabinejad M, Christiansen EL. A computed tomographic study of the distances between the maxillary sinus floor and the apices of the maxillary posterior teeth. Oral Surg Oral Med Oral Pathol. 1992 Mar;73(3): 345-6. [PubMed]

9. Moon JW, Sohn DS, Heo JU. Histomorphometric analysis of maxillary sinus augmentation with calcium phosphate nanocrystal-coated xenograft. Implant Dent. 2015 Jun;24(3):

\section{3-7. [PubMed].}

10. Kwak HH, Park HD, Yoon HR, Kang MK, Koh KS, Kim HJ. Topographic anatomy of the inferior wall of the maxillary sinus in Koreans. Int $J$ Oral Maxillofac Surg. 2004 Jun;33(4): 382-8. [PubMed]

11. Koppe T, Nakatsukasa M, Yamanaka A. Implication of craniofacial morphology for the pneumatization pattern of the human alveolar process. Acta Medica Lituanica. 2005; 12(1):40-46.

12. Ariji Y, Obayashi N, Goto M, Izumi M, Naitoh M, Kurita K, et al. Roots of the maxillary first and second molars in horizontal relation to alveolar cortical plates and maxillary sinus: computed tomography assessment for infection spread. Clin Oral Investig. 2006 Mar;10(1):35-41. [PubMed]

13. Ariji Y, Ariji E, Yoshiura K, Kanda S. Computed tomographic indices for maxillary sinus size in comparison with the sinus volume. Dentomaxillofac Radiol. 1996 Jan; 25(1):19-24. [PubMed] 
14. Moore CC, Bromwich M, Roth K, Matic DB. Endoscopic anatomy of the orbital floor and maxillary sinus. Anatomic studies. J Craniofacial Surg. 2008 Jan;19(1):271-6. [PubMed]

15. Jaffin RA, Berman CL. The excessive loss of Branemark fixtures in type IV bone: A 5-year analysis. $J$ Periodontol. 1991 Jan;62(1):2-4. [PubMed]

16. Widmark G, Andersson B, Carlsson GE, Lindvall AM, Ivanoff CJ. Rehabilitation of patients with severely resorbed maxillae by means of implants with or without bone grafts: a 3- to 5-year follow-up clinical report. Int J Oral Maxillofac Implants. 2001 Jan-Feb;16(1):73-9. [PubMed]

17. Srouji S, Ben-David D, Lotan R, Riminucci M, Livne E, Bianco P. The innate osteogenic potential of the maxillary sinus (Schneiderian) membrane: an ectopic tissue transplant model simulating sinus lifting. Int $J$ Oral Maxillofac Surg. 2010 Aug; 39(8):793-801. [PubMed]

18. Barone A, Santini S, Sbordone
L, Crespi R, Covani U. A clinical study of the outcomes and complications associated with maxillary sinus augmentation. Int J Oral Maxillofac Implants. 2006 Jan-Feb;21(1):81-5. [PubMed]

19. Korkut B. Simulating natural dental outlook in esthetic dentistry: a case report. Int J Med Sci Clin Invent. 2016; 3(9):2088-99. [Internet]

20. Kurian B, Swapna DV, Khatib MS, Nadig RR. Anterior aesthetic rehabilitation: a case report. Int J Appl Dental Sci. 2018; 4(1):6-8. [Internet]

Please cite this article as: Konstantinova D, Nenova-Nogalcheva A. Case Report about the prosthetics with intraosseous implants of the maxilla. J of IMAB. 2021 Oct-Dec;27(4):4068-4071. DOI: https://doi.org/10.5272/jimab.2021274.4068

Received: 16/03/2021; Published online: 26/10/2021

Address for correspondence:

Desislava Konstantinova

Medical University - Varna,

84, Tsar Osvoboditel str., Varna, Bulgaria

E-mail: dr.konstantinova@gmail.com 